\title{
ATTENUATION OF HAEMODYNAMIC RESPONSES FOLLOWING ENDOTRACHEAL INTUBATION: A COMPARISON BETWEEN MAGNESIUM SULPHATE AND LIDOCAINE
}

\author{
Suhail Bandey1, Vivek Singh ${ }^{2}$ \\ ${ }^{1}$ Senior Resident, Department of Anaesthesia and Critical Care, GIPMER, New Delhi. \\ ${ }^{2}$ Assistant Professor, Department of Anaesthesia and Critical Care, Rama Medical College, Kanpur, Uttar Pradesh.
}

\begin{abstract}
\section{BACKGROUND AND AIM}

Search for ideal agent to attenuate pressor response to endotracheal intubation has been a never ending process. This study compares efficacy of magnesium sulphate with lidocaine for attenuation of haemodynamic response to endotracheal intubation in patients undergoing GA.
\end{abstract}

\section{MATERIALS AND METHOD}

Ninety ASA-I and II patients between 18-55 yrs. scheduled for routine surgical procedures under GA requiring endotracheal intubation were randomly allocated to three groups of thirty patients each. Group $M$ (Magnesium sulphate group) received magnesium sulphate $(30 \mathrm{mg} / \mathrm{kg}$ ) diluted with $10 \mathrm{~mL} \mathrm{NS}$, group L (Lidocaine group) received lidocaine (1.5 mg/kg) diluted with 10 mL NS, group C (Control) received $10 \mathrm{~mL}$ of NS, intravenously over 1 min prior to intubation. HR, SBP, DBP, MAP and SpO 2 were recorded at T1-5 min before administration of sample drug, T2-just before intubation, T3-1 min after intubation, T4-3 min after intubation, T5-5 min after intubation.

\section{STATISTICAL ANALYSIS USED}

SPSS 12 and ANOVA, Unpaired ' $t$ ' test and Tukey test were used to analyse data.

\section{RESULTS}

Haemodynamic response to endotracheal intubation was significantly $(\mathrm{P}<0.05)$ attenuated in magnesium sulphate group than Lidocaine group, though latter also showed attenuation. No significant adverse effects were noted with either of these drugs.

\section{CONCLUSION}

Magnesium sulphate can safely and effectively be advocated for blunting pressor response to endotracheal intubation.

\section{KEYWORDS}

Magnesium Sulphate, Lidocaine, Heart Rate, Systolic blood pressure, Diastolic blood pressure, Mean Arterial Pressure, Pressor Response.

HOW TO CITE THIS ARTICLE: Bandey S, Singh V. Attenuation of haemodynamic responses following endotracheal intubation: a comparison between magnesium sulphate and lidocaine. J. Evolution Med. Dent. Sci. 2016;5(46):2895-2899, DOI: $10.14260 /$ jemds/2016/675

\section{INTRODUCTION}

Increase in heart rate and blood pressure are well documented sequelae of direct laryngoscopy and endotracheal intubation. 1,2,3,4,5 The haemodynamic changes stemming from airway instrumentation are due to sympathoadrenal discharge caused by epipharyngeal and parapharyngeal stimulations. The response is transient occurring 30 seconds after intubation and lasting for less than 10 minutes. ${ }^{6}$ These changes are evident as increase in blood pressure (by 40-50\%) and heart rate (by 20\%). The rise in the pulse rate and blood pressure is usually variable and unpredictable. Usually, these changes are well tolerated by healthy individuals, although they may be hazardous in patients with hypertension, coronary artery disease, cerebrovascular disease, myocardial infarction and thyrotoxicosis. ${ }^{7}$

Pressor response to intubation is exaggerated in hypertensive patients even though rendered normotensive

Financial or Other, Competing Interest: None.

Submission 26-04-2016, Peer Review 15-05-2016,

Acceptance 21-05-2016, Published 08-06-2016.

Corresponding Author:

Dr. Suhail Bandey,

House No. WZ 485/9A, $3^{\text {rd }}$ Floor,

Basaidarapur-110015,

New Delhi.

E-mail: suhailbandey@gmail.com

DOI: $10.14260 /$ jemds/2016/675 preoperatively by antihypertensive medications. ${ }^{8}$ Pressor response may result in intra-operative myocardial infarction, acute L.V.F, dysarhythmias, ${ }^{9}$ and intracerebral bleed in individuals with end organ decompensation.

To 'blunt' this pressor response different pharmacological agents like lidocaine, vasodilators, drugs inhibiting sympathoadrenal response, $\alpha$ - and $\beta$-adrenergic blockers and opioids have been tried in the past.10,11,12,13,14 These methods require administration of additional costly drugs, which not only have no role for induction and maintenance of anaesthesia, but also can cause dangerous complications.

Lidocaine is used topically to relieve itching, burning and pain from skin inflammations, injected as a dental anaesthetic or as a local anaesthetic for minor surgery. It has been used as lidocaine gargle for oropharyngeal anaesthesia, as a lidocaine aerosol for endotracheal anaesthesia or as an intravenous bolus for systemic anaesthesia. Intravenous lidocaine, in particular, has been found to suppress the cough reflex to prevent increases in intracranial pressure to attenuate circulatory responses and to possess antiarrhythmic properties. ${ }^{15}$ Its efficacy has been reported for use as a topical as well as in intravenous form. 16.17,18,19

Magnesium sulphate is used to attenuate haemodynamic stress response during laryngoscopy and endotracheal intubation. Magnesium is the fourth most abundant cation in the body and the second most abundant intracellular cation. 
It activates many of the enzyme systems. It is also involved in several physiological processes like control of vasomotor tone, cardiac excitability and neurotransmitter release. In many of its actions, it is likened to a physiological calcium antagonist.

Magnesium sulphate has direct vasodilating property on coronary arteries and inhibits catecholamine release, but seems to produce mild increase in heart rate because of its predominant effect on inhibition of release of acetylcholine from the vagus nerve. Magnesium sulphate potentiates nondepolarising muscle relaxants, thereby prolonging the effects of non-depolarising muscle relaxants. Both the drugs have been varyingly reported to be effective against haemodynamic reflex, hence the present study was planned to compare and evaluate the efficacy of both the drugs in patients undergoing endotracheal intubation under general anaesthesia.

\section{SUBJECTS AND METHODS}

The study was a prospective, randomized controlled trial and carried out in the Department of Anaesthesiology, Era's Lucknow Medical College and Hospital, Lucknow.

90 Adults in the age group of 18-55 years ASA I and II scheduled for surgery under general anaesthesia were studied after obtaining the clearance from Hospital Ethical Committee. Patients with anticipated difficult intubation: Mallampati grade III and IV, significant coronary artery disease or ischaemic heart disease, chronic pulmonary disease, renal failure, hepatic dysfunction, morbid obesity, moderate or severe anaemia ( $\mathrm{Hb}$ less than $9 \mathrm{gm} \%$ ), history of malignant hyperthermia, history of hypertension (SBP >140 mmHg, DBP $>90 \mathrm{mmHg}$ ), sensitive to lidocaine and magnesium sulphate were excluded from the study.

Written and informed consent was obtained from eligible patients. The patients were visited a day prior to surgery for pre-anaesthetic review and standard institutional preoperative advice was given. On arrival of patients in the operation theatre, intravenous line was initiated with 18G cannula. Preoperative recording of Heart Rate (HR), noninvasive blood pressure (systolic and diastolic) and arterial oxygen saturation $\left(\mathrm{SpO}_{2}\right)$ was made.

The patients were randomly allocated into three groups, group M (Magnesium sulphate), group L (Lidocaine) and group C (Control) of 30 patients each: Group M ( $n=30)$ were injected with Inj. Magnesium sulphate $30 \mathrm{mg} / \mathrm{kg}$ intravenously over one minute. Group L $(n=30)$ were injected with Inj. Lidocaine $1.5 \mathrm{mg} / \mathrm{kg}$ intravenously over one minute. Group C $(\mathrm{n}=30)$ were injected with $10 \mathrm{~mL}$ NS (Normal saline) over one minute. (Inj. Magnesium Sulphate and Inj. Lidocaine were diluted to $10 \mathrm{~mL}$ with normal saline prior to injection).

The study drug was administered before laryngoscopy and intubation. All the patients were pre-oxygenated with $100 \%$ oxygen for 3 minutes. Sample drug was thereafter injected over a period of one minute followed by induction of anaesthesia with Inj. Sodium thiopentone $5 \mathrm{mg} / \mathrm{kg}$. Patients were intubated following the administration of paralyzing dose of Inj. Succinylcholine $1.5 \mathrm{mg} / \mathrm{kg}$ intravenously. Anaesthesia was maintained with $40 \%$ oxygen in nitrous oxide and halothane delivered through Bain's circuit using IPPV. Muscle relaxation was achieved with Inj. Atracurium 0.5 $\mathrm{mg} / \mathrm{kg}$ followed by incremental doses of Inj. Atracurium 0.1 $\mathrm{mg} / \mathrm{kg}$.

At the conclusion of surgery residual muscle paralysis was reversed with Inj. Neostigmine $50 \mu \mathrm{g} / \mathrm{kg}$ and Inj. Glycopyrrolate $10 \mu \mathrm{g} / \mathrm{kg}$ intravenously. The patients were extubated following return of regular, rhythmic respiration when reasonably awake.

The heart rate and blood pressure (systolic, diastolic and mean), oxygen saturation $\left(\mathrm{SpO}_{2}\right)$ were recorded 5 mins before administration of sample drug (T1), after administration of sample drug but just before intubation (T2), one minute after intubation (T3), three minutes after intubation (T4) and five minutes after intubation, but before surgical incision (T5).

The observations made during above study were recorded on a proforma and the results obtained were analysed by appropriate statistical tests such as SPSS 12 and ANOVA, Unpaired ' $\mathrm{t}$ ' test and Tukey test.

\section{RESULTS}

Statistically, no significant intergroup difference was observed for any of the parameters. All the three groups were matched for age, gender, surgical complexity, weight, height and BMI (Table 1).

At baseline, there was no significant difference among the groups and the groups were matched $(\mathrm{p}=0.173)$. However, at all the subsequent time intervals, MAP was maximum in Group $\mathrm{C}$ and minimum in Group $\mathrm{M}$. The differences among groups were significant statistically at T3, T4 and T5 intervals (Table 2 \& Fig. 1).

At baseline T1, mean SBP in three groups showed no significant intergroup differences $(\mathrm{p}=0.551)$, thereby implying that the groups were comparable at baseline. At all the subsequent time intervals, mean value was maximum in Group $\mathrm{C}$ and minimum in Group M. However, the difference among groups was significant statistically only at T3, T4 and T5 intervals (Fig. 2).

At baseline there was no significant difference among the groups $(p=0.115)$, thereby indicating that the groups were matched at baseline. At all the subsequent time intervals, mean DBP was maximum in Group C and minimum in Group M. The differences among groups were significant statistically at T3, T4 and T5 intervals (Fig. 3).

At baseline, Mean Heart Rate (HR) in all the three groups did not show a significant difference statistically $(\mathrm{p}=0.355)$, thus implying that the groups were matched for heart rate at baseline. Statistically, no significant difference in mean heart rate of different groups was observed at $\mathrm{T} 2$ too $(\mathrm{p}=0.074)$. However, at T3, T4 and T5 intervals a statistically significant difference in mean heart rate was observed among the groups $(\mathrm{p}<0.001)$ with mean heart rate in Group $\mathrm{C}$ being maximum, whereas the same was minimum in Group L at T3 and Group $\mathrm{M}$ at T4 and T5 (Table 3 \& Fig. 4).

Patients in all the three groups maintained oxygen saturation between $99-100 \%$ at all the time during the study period and thereafter.

None of the adverse effects attributable to either of the study drugs were observed in any of the patients. 


\begin{tabular}{|c|c|c|c|c|c|}
\hline Sl. No. & Variable & Group C & Group M & Group L & Significance of Difference \\
\hline 1. & Mean Age \pm SD (yrs.) & $40.34 \pm 9.73$ & $38.87 \pm 8.32$ & $40.88 \pm 11.41$ & $\mathrm{~F}=0.331 ; \mathrm{p}=0.719$ \\
\hline 2. & Male:Female & $16: 14$ & $14: 16$ & $14: 16$ & $\chi^{2}=0.356 ; \mathrm{p}=0.837$ \\
\hline 3. & ASA Gr I/II & $21 / 9$ & $18 / 12$ & $20 / 10$ & $\chi^{2}=0.689 ; \mathrm{p}=0.709$ \\
\hline 4. & Mean Weight \pm SD $(\mathrm{kg})$ & $52.6 \pm 9.7$ & $54.3 \pm 10.8$ & $51.3 \pm 11.7$ & $\mathrm{~F}=0.586 ; \mathrm{p}=0.559$ \\
\hline 5. & Mean Height \pm SD $(\mathrm{cm})$ & $159.8 \pm 16.5$ & $156.4 \pm 18.4$ & $155.3 \pm 13.3$ & $\mathrm{~F}=0.629 ; \mathrm{p}=0.536$ \\
\hline 6. & Mean BMI \pm SD $\left(\mathrm{kg} / \mathrm{m}^{2}\right)$ & $20.81 \pm 4.3$ & $22.31 \pm 5.1$ & $21.35 \pm 4.7$ & $\mathrm{~F}=0.780 ; \mathrm{p}=0.462$ \\
\hline \multicolumn{6}{|r}{ Table 1: Demographic Comparison of Patients in Three Groups } \\
\hline
\end{tabular}

\begin{tabular}{|c|c|c|c|c|c|c|c|c|c|}
\hline \multirow{2}{*}{ Sl. No. } & \multirow{2}{*}{ Time Interval } & \multicolumn{2}{|c|}{ Group C } & \multicolumn{2}{c|}{ Group M } & \multicolumn{2}{c|}{ Group L } & \multicolumn{2}{c|}{ Significance of Difference (ANOVA) } \\
\cline { 2 - 10 } & & Mean & SD & Mean & SD & Mean & SD & F & "p" \\
\hline 1. & $\mathrm{~T} 1$ & 92.80 & 5.45 & 96.22 & 8.71 & 94.33 & 6.46 & 1.793 & 0.173 \\
\hline 2. & $\mathrm{~T} 2$ & 94.02 & 6.09 & 90.22 & 8.33 & 91.50 & 6.33 & 2.295 & 0.107 \\
\hline 3. & $\mathrm{~T} 3$ & 104.93 & 10.32 & 84.14 & 6.61 & 94.36 & 5.23 & 54.821 & $<0.001$ \\
\hline 4. & $\mathrm{~T} 4$ & 113.67 & 7.26 & 83.67 & 7.47 & 104.71 & 5.30 & 156.45 & $<0.001$ \\
\hline 5. & Table 2: Comparison of Mean MAP in Three Groups at Different Time Intervals \\
\hline \multicolumn{10}{|c|}{}
\end{tabular}

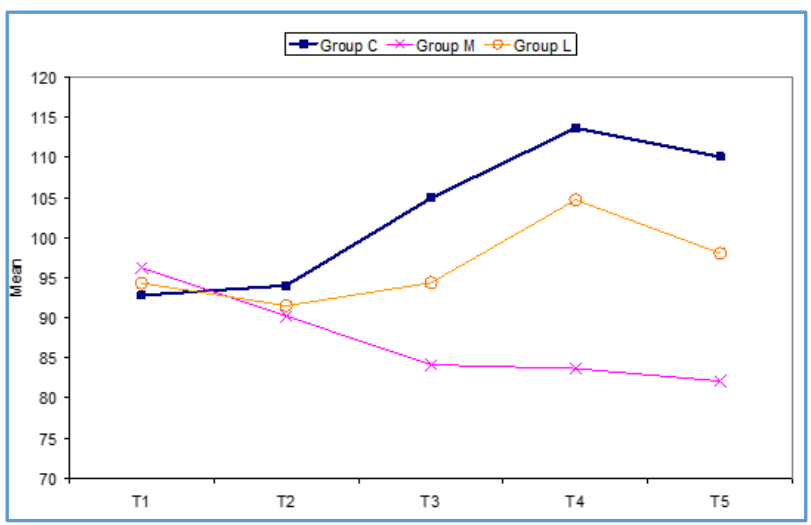

Fig. 1: Within Group Change in MAP at Different Time Intervals

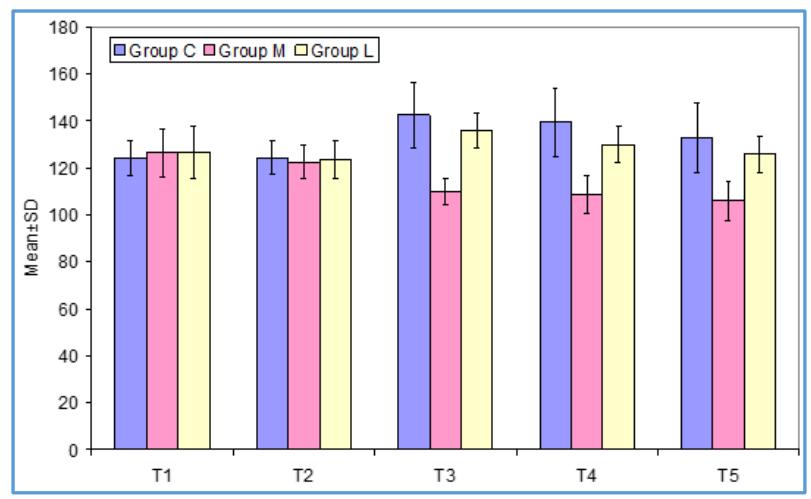

Fig. 2: Comparison of Mean SBP in Three Groups at Different Time Intervals

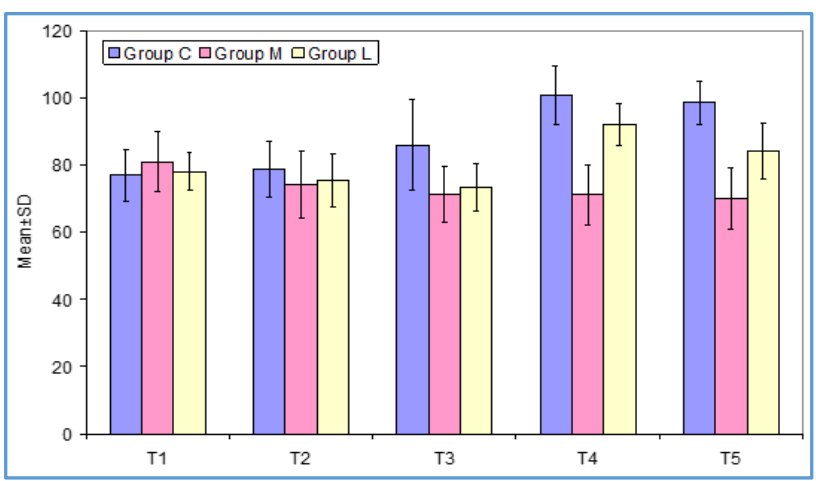

Fig. 3: Comparison of Mean DBP in Three Groups at Different Time Intervals

\begin{tabular}{|c|c|c|c|c|c|c|c|c|c|}
\hline \multirow[t]{2}{*}{ SN. } & \multirow[t]{2}{*}{$\begin{array}{c}\text { Time } \\
\text { Interval }\end{array}$} & \multicolumn{2}{|c|}{ Group C } & \multicolumn{2}{|c|}{ Group M } & \multicolumn{2}{|c|}{ Group L } & \multicolumn{2}{|c|}{$\begin{array}{l}\text { Significance of } \\
\text { Difference } \\
\text { (ANOVA) }\end{array}$} \\
\hline & & Mean & SD & Mean & SD & Mean & SD & $\mathbf{F}$ & “p” \\
\hline 1. & T1 & 80.67 & 10.30 & 79.80 & 5.31 & 82.73 & 7.82 & 1.047 & 0.355 \\
\hline 2. & $\mathrm{~T} 2$ & 82.83 & 6.18 & 82.20 & 6.13 & 78.93 & 8.42 & 2.690 & 0.074 \\
\hline 3. & T3 & 92.27 & 10.69 & 82.80 & 6.63 & 81.47 & 8.80 & 13.238 & $<0.001$ \\
\hline 4. & $\mathrm{~T} 4$ & 103.70 & 11.79 & 92.77 & 5.43 & 94.50 & 4.37 & 16.576 & $<0.001$ \\
\hline 5. & $\mathrm{~T} 5$ & 105.70 & 19.05 & 93.07 & 4.97 & 95.83 & 4.29 & 9.776 & $<0.001$ \\
\hline
\end{tabular}

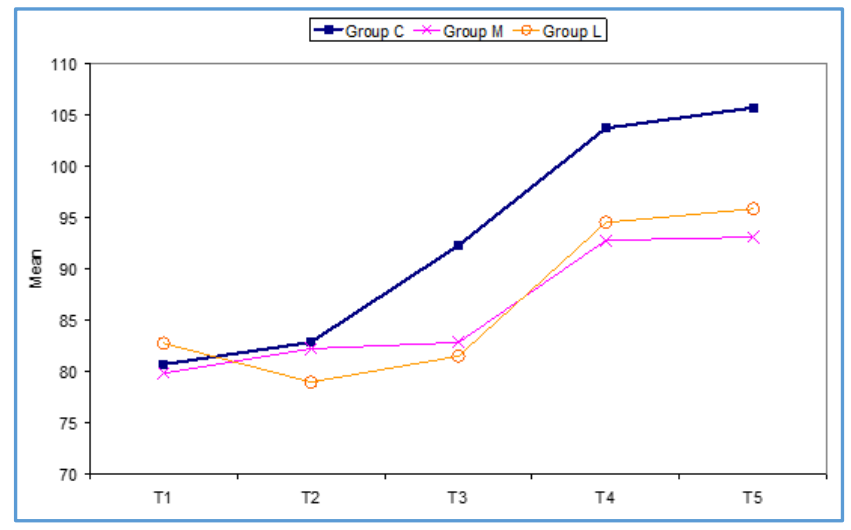

Fig. 4: Within Group Change in Heart Rate at Different Time Intervals

\section{DISCUSSION}

Increases in heart rate and blood pressure are the principal changes in the cardiovascular system during laryngoscopy and tracheal intubation. Stimulus of the laryngeal and tracheal tissues may also cause increase in both sympathetic and sympathoadrenal reflex activity. The role of magnesium sulphate in blunting the intubation response is evolving. Magnesium has direct vasodilating properties on coronary arteries and inhibits catecholamine release, thus attenuates the haemodynamic effects during endotracheal intubation.

In present study, an attempt has been made to evaluate and compare the efficacy of injection Magnesium sulphate and injection Lidocaine for attenuation of pressor response during endotracheal intubation in patients undergoing general anaesthesia.

Ahmad (2009) ${ }^{20}$ in his study evaluated the efficacy of preoperative intravenous administration of magnesium sulphate $50 \mathrm{mg} / \mathrm{kg}$ in reducing stress response to laryngoscopy and intubation. He observed a statistically 
significant increase in heart rate, systolic blood pressure, diastolic blood pressure and mean arterial pressure from baseline onwards to all the post intubation intervals in control group. In the present study, a similar observation was obtained on comparing the magnesium sulphate group with control group with respect to heart rate, systolic blood pressure, diastolic blood pressure and mean arterial pressure.

Santiveri et al(1998).21 in their study on attenuation of haemodynamic response to laryngoscopy and tracheal intubation, observed the heart rate to be lower significantly with lidocaine (1 $\mathrm{mg} / \mathrm{kg}$ intravenous pre-treatment) after intubation and 3 and 5 minutes thereafter when compared to baseline values. In the present study, however, a rising trend in HR was observed from 'after intubation' (T3) till 5 minutes 'after intubation' (T5) following pre-treatment with lidocaine $1.5 \mathrm{mg} / \mathrm{kg}$ intravenously.

Trivedi and Patel (2009)22 compared intravenous magnesium sulphate $30 \mathrm{mg} / \mathrm{kg}$ with buprenorphine $3 \mu \mathrm{g} / \mathrm{kg}$ given 3 minutes before intubation. They found that magnesium sulphate attenuated the pressor response to laryngoscopy and endotracheal intubation adequately. Similar results were observed with magnesium sulphate $30 \mathrm{mg} / \mathrm{kg}$ given before intubation in the present study.

James et al (1989) ${ }^{23}$ studied the pre-treatment with 60 $\mathrm{mg} / \mathrm{kg}$ of magnesium sulphate intravenously on cardiovascular responses associated with endotracheal intubation. They concluded that magnesium sulphate attenuated the cardiovascular response after tracheal intubation. Similar results were obtained in the present study with magnesium sulphate intravenous pre-treatment in a dose of $30 \mathrm{mg} / \mathrm{kg}$ only.

In the present study, immediately after administration of drug an increase in systolic blood pressure was observed in Group C, whereas in both the study groups i.e. Groups L and M a decrease in systolic blood pressure was noted. Though the increase in control group was not significant statistically, the decrease in both the study groups showed a significant change from baseline. Immediately after intubation, an increase in blood pressure was observed in Group C. Though, for systolic blood pressure and MAP such increase was observed in Group L too, but for DBP a decrease in blood pressure was observed in Group L immediately after intubation. In contrast for all the three parameters, magnesium sulphate showed a significant decrease immediately after intubation. At all the postintubation time intervals, mean values for blood pressure were lower in Group M as compared to Groups C and L. Group $\mathrm{L}$ also had lower mean values for all the three parameters as compared to Group C, but had higher mean values as compared to Group M.

Magnesium sulphate group showed a slight increase in heart rate immediately after administration, though the change was not significant statistically. Immediately after intubation, it showed significantly lower mean value as compared to Group C, but was found to be comparable to Group L. At subsequent intervals, Group M had mean heart rate which was significantly higher as compared to baseline, but significantly lower as compared to Group C. Mean heart rate was comparable between Groups $\mathrm{L}$ and $\mathrm{M}$ at all time intervals. Group C showed worst control over heart rate in postintubation intervals, whereas Group M showed maximum control over heart rate in post-intubation intervals.
Thus, with respect to heart rate, magnesium sulphate and lidocaine showed a good control. Despite the increase in heart rate being significant statistically as compared to baseline, it was not significant statistically when lidocaine group was compared to magnesium sulphate group.

Puri et al (1998) 24 in a study on pre-treatment with magnesium sulphate for attenuation of pressor response to laryngoscopy observed that magnesium sulphate resulted in a rapid but transient decrease in systemic vascular resistance thus, bringing about a sudden decrease in the blood pressure. The results in present study are consistent with the observations made by Puri et al (1998) ${ }^{24}$ who also experienced attenuating effect of magnesium sulphate for haemodynamic reflex during endotracheal intubation. Magnesium group had a better haemodynamic control as compared to lidocaine and control groups. Again, in the present study blood pressure (SBP, DBP and MAP) was significantly lower in the magnesium sulphate group.

Lidocaine has been used to attenuate cardiovascular responses during endotracheal intubation with varied results. However, the results in present study were in consistence with the studies by Puri et al (1998),24 Naghibi and Akhtari (2000). ${ }^{25}$ and Montazeri et al (2005) ${ }^{26}$. The cardiovascular effects observed in this study were particularly interesting. It might be expected that magnesium would slow the atrial rate by inhibiting the calcium mediated depolarizing current in pacemaker tissue, an effect that has been demonstrated in isolated animal hearts. However, in the intact animal the ability of magnesium to inhibit the release of acetylcholine from the vagus nerve predominates and therefore the overall effect is the mild increase in heart rate.

Heart rate after intubation in the control group was significantly higher than in the magnesium and lidocaine groups. James et al23 attributed this to the fact that epinephrine levels in the magnesium group did not increase above baseline values, whereas in the control group there was a significant increase in epinephrine levels. In the present study, however, heart rate tended to go above the baseline in magnesium sulphate group.

The vasodilator effects of magnesium sulphate are characterized by a mild and transient decrease in blood pressure associated with peripheral vasodilatation and a consistent increase in cardiac index (James et al. 1987).27 Magnesium also reduces the responsiveness of vascular smooth muscle to norepinephrine stimulation. In the present study, rise in blood pressure was less in the magnesium sulphate group than in other two groups, whereas changes in heart rate were comparable in lidocaine and magnesium sulphate group.

Lidocaine when compared to magnesium sulphate showed a comparable control over heart rate, but a poor control over blood pressure, though for both the responses, it had a better control as compared to control group. These results are similar to those obtained by a number of workers (Puri et al., 1998; 2005 Naghibi and Akhtari; 2000 Montazeri and Fallah).24,25,26

Magnesium sulphate has been known to potentiate the effects of muscle relaxants. ${ }^{28}$ In the present study, a similar trend was observed with magnesium sulphate, though the analysis of same was beyond the scope of the present study.

\section{CONCLUSION}

Both Magnesium sulphate and Lidocaine showed attenuation to pressor response to endotracheal intubation. However, in 
view of the better haemodynamic control observed during endotracheal intubation, Magnesium sulphate can safely and effectively be recommended for use in attenuation of pressor response to endotracheal intubation in patients undergoing surgeries under general anaesthesia.

\section{KEY MESSAGE}

Magnesium sulphate had significantly lower systolic, diastolic and mean arterial blood pressure as compared to lidocaine and control groups at all the post-intubation intervals. Magnesium sulphate can safely and effectively be recommended for use in attenuation of pressor response to endotracheal intubation in patients undergoing surgeries under general anaesthesia.

\section{REFERENCES}

1. Singh SP, Quadir A, Malhotra P. Comparison of esmolol and labetalol, in low doses, for attenuation of sympathomimetic response to laryngoscopy and intubation. Saudi J Anaesth 2010;4(3):163-8.

2. King BD, Harris L, Greifenstein F, et al. Reflex circulatory responses to direct laryngoscopy \& intubation under general anaesthesia. Anaesthesiology 1951;12(5):55666.

3. Takeshima Koji, Noda Kengo, Higaki Masaaki. Cardiovascular responses to endotracheal intubation. Anaesthesia Analgesia 1964;43(2):201-8.

4. Forbes AM, Dally FG. Acute hypertension during induction and endotracheal intubation in normotensive man. British journal of Anaesthesia 1970;42(7):618-24.

5. Reid LC, Brace DE. Irritation of the respiratory tract and its reflex effect upon heart. Surg Gynaec \& Obst 1940;70:157-62.

6. Stoelting RK. Circulatory changes during direct laryngoscopy and tracheal intubation: influence of duration of laryngoscopy with or without lidocaine. Anaesthesiology 1977;47(4):381-4.

7. Fox EJ, Sklar GS, Hill CH, et al. Complications related to pressor response to endotracheal intubation. Anaesthesiology 1977;47(6):524-5.

8. Cedric Preys Robert. Anaesthesia and hypertension. British journal of Anaesthesia 1984;56:711-24.

9. Ronal D Miller. Miller's anaesthesia. Elsevier Churchill Livingstone $6^{\text {th }}$ edn, 2005; Vol 2:p 3203.

10. Helfmann SM, Gold MI, Delisser EA. Which drug prevents tachycardia and hypertension associated with tracheal intubation lignocaine, fentanyl or esmolol. Anaesth Analg 1991;72(4):482-6.

11. Sharma J, Sharma V, Ranbushan, et al. Comparative study of magnesium sulphate and esmolol in attenuating the pressor response to endotracheal intubation in controlled hypertensive patients. J Anaesth Clin Pharmacol 2006;22(3):255-9.

12. Mikawa K, Nishina $\mathrm{K}$, Maekawa N, et al. Comparison of nicardipine, diltiazen and verapamil for controlling the cardiovascular responses to tracheal intubation. $\mathrm{Br} \mathrm{J}$ Anaesth 1996;76(2):221-6.

13. Kindler CH, Schumacher PG, Schneider MC, et al. Effects of intravenous lidocaine and/or esmolol on haemodynamic responses to laryngoscopy and intubation: a double-blind, controlled clinical trial. J Clin Anaesth 1996;8(6):491-6.
14. Saitoh N, Mikawa K, Kitamura S, et al. Effects of trimetaphan on the cardiovascular response to tracheal intubation. Br J Anaesth 1991;66(3):340-4.

15. Tam S, Chung F, Campbell M. Intravenous lidocaine: optimal time of injection before tracheal intubation. Anaesth Analg 1987;66(10):1036-8.

16. Abou Madi MN, Keszler H, Yacoub JM. Cardiovascular reactions to laryngoscopy and tracheal intubation following small and large i.v doses of lidocaine. Can Anaesth Soc J 1977;24(1):12-9.

17. Stoelting RK. Blood pressure and heart rate changes during short-duration laryngoscopy for tracheal intubation: influence of viscous or intravenous lidocaine. Anaesth Analg 1978;57(2):197-9.

18. Mostafa SM, Murthy BV, Barrett PJ, et al. Comparison of the effects of topical lignocaine spray applied before or after induction of anaesthesia on the pressure response to direct laryngoscopy and intubation. European Journal of Anaesthesiology 1999;16(1):7-10.

19. Takita K, Morimoto Y, Kemmotsu O. Tracheal lidocaine attenuates the cardiovascular response to endotracheal intubation. Can J Anaesth 2001;48(8):732-6.

20. Ahmad AA. Treatment of stress response to laryngoscopy and intubation with magnesium sulphate. El-Minia Med Bull 2009;20(2):191-6.

21. Santiveri X, Ledesma M, Delás F, et al. Comparison of lidocaine and urapidil for prevention of haemodynamic response to tracheal intubation in patients in general good health. Rev Esp Anaestesiol Reanim 1998;45(2):469.

22. Trivedi V, Patel RA. Comparative study of efficacy of intravenous magnesium sulphate versus buprenorphine for attenuating the pressor response to laryngoscopy and intubation. J Anaesth Clin Pharmacol 2009;25(4):459-62.

23. James MF, Beer RE, Esser JD. Intravenous magnesium sulphate inhibits catecholamine release associated with tracheal intubation. Anaesth Analg 1989;68(6):772-6.

24. Puri GD, Marudhachalam KS, Chari P, et al. The effect of magnesium sulphate on haemodynamics and its efficacy in attenuating the response to endotracheal intubation in patients with coronary artery disease. Anaesth Analg 1998;87(4):808-11.

25. Naghibi KH, Akhtari M. Attenuation of the pressor response to tracheal intubations by magnesium sulphate. Journal of Research in Medical Sciences 2000;5(1):42-4.

26. Montazeri K, Fallah M. A dose-response study of magnesium sulphate in suppressing cardiovascular responses to laryngoscopy \& endotracheal intubation. Journal of Research in Medical Sciences 2005;10(2):826.

27. James MFM, Cork RC, Dennett JE. Cardiovascular effects of magnesium sulphate in the baboon. Magnesium 1987;6(6):314-24.

28. Ghonheim MM, Long JP. The interaction between magnesium and other neuromuscular blocking agents. Anaesthesiology 1970;32:23-6. 